Francisco, CA). The quarter, furthermore, ended on a high note, with 13 companies in registration, including eight secondary offerings and five IPOs.

Last year also saw biotech companies raise about $\$ 1.2$ billion through private financing. In fact, a host of public companies conducted private offerings, though their stock generally sold at a 15 to 20 percent discount from public-market prices. For its part, the fourth quarter saw at least 21 companies take in \$238.7 million through private offerings.

- In October, four firms captured $\$ 21$ million, as Celtrix Pharmaceuticals (Santa Clara, CA) netted \$12 million, Progenics Pharmaceuticals
(Tarrytown, NY) brought in \$5.1 million, MedClone (Los Angeles, CA) snared $\$ 2$ million, and AgroCultures Biotechnologies (Montreal) brought home $\$ 1.9 \mathrm{mil}$ lion.

- In November, 10 companies took home \$126.2 million, with Amrad (Victoria, Australia) snaring $\$ 44$ million, Aviron (Burlingame, CA) capturing $\$ 15$ million, Somatogen (Boulder, CO) netting \$14.7 million, Cortex Pharmaceuticals (Irvine, CA) grabbing $\$ 13.75$ million, Univax Biologics (Rockville, MD) bringing in $\$ 10.7$ million, Ascent Pharmaceuticals (Billerica, MA) raising $\$ 8.2$ million, Pharmacopeia (Princeton, NJ) snaring $\$ 7$ million, Neoprobe (Colum- bus, $\mathrm{OH}$ ) taking home $\$ 6.6$ million, BioNebraska (Lincoln, NE) capturing \$5.5 million, and TransGenic Systems (Bozeman, MT) netting $\$ 705,000$.

- And December saw seven companies raise $\$ 91.5$ million, as Isis Pharmaceuticals (Carlsbad, CA) brought in $\$ 20.3$ million, $T$ Cell Sciences (Cambridge, MA) snared $\$ 18$ million, Cell Therapeutics (Seattle, WA) grabbed $\$ 13.9$ million, Alexion Pharmaceuticals (New Haven, CT) took in $\$ 13$ million, Somatix Therapy (Alameda, CA) captured $\$ 11$ million, Therexsys (Keele, U.K.) netted $\$ 9.6$ million, and BioCad (Mountain View, CA) took home $\$ 5.7$ million.

-B.J. Spalding

\title{
1994 will see stocks trade on own merits
}

\section{R. Brandon Fradd is managing director at Montgomery Securities (San Francisco, $C A$ ).}

The continuing investment theme in biotech is stock selection, rather than group selection. We began to see mixed performance in biotech stocks in last year's second quarter, with some stocks reaching new highs and others reaching new lows. We expect this trend to continue for at least the next year, believing it reflects a more selective interest in all health-care stocks by investors. The changes occurring in the industry suggest that there will be "winners" and "losers," and investors are trying to assess which is which.

We are also seeing a new trend in biotech: a divergence from pharmaceutical stocks. In the third quarter of 1993-for the first time in three years-biotech stocks went up, while those of drug companies went down. Biotech stocks were up 5.0 percent for the third quarter, though our index shows that at the quarter's end biotech stocks were still down 17 percent for the year, with the first tier down 5.4 percent, the second tier down 11.2 percent, and the third tier down 25.7 percent. Our index of drug-company stocks, for its part, was down 10.6 percent for the year at that time. In the past, biotech stocks have gone in the same direction as drug-company stocks, but to a greater degree, reflecting their greater volatility. Now we are seeing a trend in which investors are viewing biotech companies-be- cause they are largely a source of new drugs - as distinct from drug companies, many of which are plagued by the prospect of generic competition.

We would overweight biotech stocks this year. The group will be lead by two companies with expected earnings acceleration in 1994: Chiron (Emeryville, CA) and Genentech (S. San Francisco, CA). The group's previous leader, Amgen (Thousand Oaks, CA), should also see growth in 1994 and accelerated growth in 1995. By contrast, the focal point in 1992 was Centocor's (Malvern, PA) lack of Food and Drug Administration (Bethesda, MD) approval for Centoxin, while the focal points in 1993 were Amgen's disappointing first quarter earnings and Synergen's (Boulder, $\mathrm{CO})$ disappointing trial of Antril.

We also have seen several biotech companies move from lower to higher tiers as they mature. Several second-tier companies are likely to see positive results in phase III trials in 1994, including Advanced Tissue Sciences (La Jolla, CA), Creative BioMolecules (Hopkinton, MA), Gensia Pharmaceuticals (San Diego, CA), Glycomed (Alameda, CA), Regeneron (Tarrytown, NY), SciClone (San Mateo, CA), and Scios Nova (Mountain View, CA). We recommend holding a portfolio of first-tier, second-tier, and third- tier companies to balance risk and reward.

We expect the measures proposed by the Clinton Administration concerning the price control of novel drugs to be abandoned in any final bill. We do not believe this issue is a sufficiently large part of healthcare costs to justify "going to the mat." We expect that firms with breakthrough products will receive premium pricing, although such pricing may have to be justified through cost-effectiveness studies. Our biggest concern for 1994 is the prospect of rising interest rates, which lowers the valuation on growth stocks, and the prospect of product disappointments, which will occur. We note, however, that the recent MedImmune (Gaithersburg, MD) disappointment did not have an impact on other stocks. This observation supports our thesis that stocks are performing individually, rather than as a group.

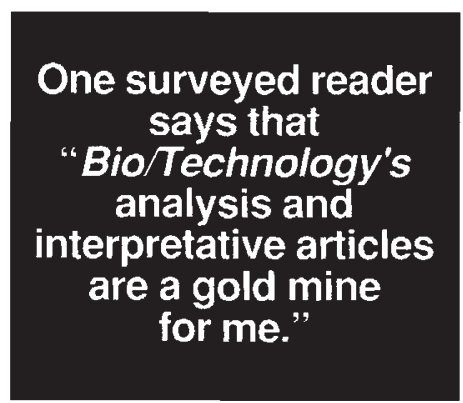

